\title{
SOCIAL MEDIA IN COMMUNICATION OF TEMPORARY ORGANISATIONS: ROLE, NEEDS, STRATEGIC PERSPECTIVE
}

\author{
Dalia RIMKUNIENE ${ }^{1}$, Virgilija ZINKEVICIUTE ${ }^{2}$ \\ ${ }^{1}$ Alumni of Heriot-Watt University, Edinburgh Campus, Riccarton, \\ Currie EH14 4AS, Edinburgh, United Kingdom \\ ${ }^{2}$ Logistic and Transport Management Department, Vilnius Gediminas Technical University, \\ Plytinès g. 27, LT-10105 Vilnius, Lithuania \\ E-mails:1'ms.r.dalia@gmail.com; ${ }^{2}$ virgilija.zinkeviciute@vgtu.lt (corresponding author)
}

Received 03 February 2014; accepted 22 June 2014

\begin{abstract}
Expansion of "projectisation" culture worldwide, "internalization" of projects and the inevitable growth of social media use globally calls for systematic and deeper insights from the strategic management viewpoint. Projects are defined as temporary organisations within various organisational bodies. In terms of the strategic management, temporary organisations are viewed as unique structural networking bodies that are anticipated to have their own strategy and management approach to meet project-based needs. Effective "project communication" plays a strategic role and can be an important enabler of social capital gains for organisations. Social media, as a new age phenomenon, are claimed to be the powerful mechanism that opens vast opportunities for collaborative communication. Their application in terms of temporary organisation is still underinvestigated area that lacks a researchers' attention. The aim of this research is to explore the potential of social media use in temporary organisations. The research study indicates that social media have a large potential for enhancing collaborative initiatives and collecting evidence for the strategic planning.
\end{abstract}

Keywords: temporary organisation, project management, communication, social media, strategic management, decisions making.

JEL Classification: D7, D83, M00, M16, O22.

\section{Introduction}

In a relatively short time, social media have become part of the business world. Surveys initiated by international bodies such as the McKinsey company (Mckinsey.com 2014), discussions held by the Project Management Institute (PMI) point out that social media participate in internal and external communication of various business companies. Barriers to use social media in the business environment are tending to melt down. But still there are many unsolved issues that fuel various debates about how project business can benefit from social media avoiding additional risks.

The concept of social media is founded on the idea of open communication, which breaks the boundaries of traditional communication. In line to positivist approach, social 
media technologies have opened new opportunities for various collaborative activities and have much to offer to meet a variety of needs. Supporting a completely new communication mode, social media make it possible to gain specific new experiences in an accelerated way through engagement in groups and networks online. The adoption of social media can likely be a very insightful and effective business management solution in project environment.

In contrast, sceptics state that to "become social" means to expose yourself and your organisation to unnecessary risk. It is believed that social media gives scale but lacks privacy. In terms of organisational bodies, social media are being criticised for security issues. There are fears of losing control over corporate information. It is argued that social media can shake organisation's balance, be a source of harmful external influence, particularly in the self-organising or open type systems.

Contrasting practices and approaches in terms of social media's role in the communication of project environments indicate the problem. There is no unanimous understanding about what tangible value social media can bring to temporary organisations, can they improve communication in projects internally and externally and ultimately become a well-established project communication strategy in the environment of temporary organisations.

Having in mind that the majority of the academic content is complex, authors of this paper have decided to turn rather multi-facetted nature of the content of the chosen phenomenon into a much simple, one-directional argument that makes the whole argumentation somewhat linear from the beginning to the very end. Therefore, in this particular research report, it was chosen to put the data according to the standard empirical papers mode, while following standard structure, starting with the introduction of main research issues and continuing with both theoretical and empirical considerations. Finally, authors of this paper invite readers to ponder on further possible outcomes and research in the analysed area.

The aim of this research is to explore the potential of social media use in temporary organisations, to identify the dominating trends of their current use and examine perceptions of their application with respect to specific needs of temporary organisations. With this purpose in mind, the research question was formulated as follows: Can social media enhance effectiveness of communication in temporary organisations by addressing specific project-based needs?

To answer the key research question, the following objectives were formulated: 1) to establish communication modes that are common in the environment of temporary organisations; 2) to identify the means of social media participating in communication of temporary organisations; 3 ) to examine the perceptions in regards to social media use to improve the effectiveness of communication in temporary organisations; 4) to identify the barriers/reservations to use social media in communication in temporary organisations. 


\section{Employing social media for communication in temporary organisations}

The concept of social media application for communication in the environment of temporary organisations is relatively new. A limited number of publications and surveys demonstrate intentions to address the topic. In practice, social media are likely to capture the attention of project managers and project teams. Practitioners are interested in how project business can benefit from the use of social media.

From a theoretical point of view the problem is complex as it overlaps three different fields of knowledge. Firstly, it requires a good understanding of the concept of the temporary organisation. This network-based complex system is a special social construct which blends permanent and temporary features and combines diverse interacting components and relationships. Secondly, it demands a good comprehension of the integral role of communication in the environment of a temporary organisation. It is said that communication in projects is responsible for binding "diversely skilled people working jointly on a task of some complexity over a limited time period" (Johannessen, Olsen 2011: 32). And thirdly, the research problem demands a critical appraisal of tangible benefits that could be offered by social media to temporary organisations.

\subsection{Temporary organisations and communication needs}

The concept of temporary organisations emerged long ago with shrinking patterns of vertical integration in industries and increasing number of network-based organisational structures based on collaborative agreements (Powell 1990; Lundin, Söderholm 1995; Bechky 2006; Marchi, Sarcina 2011). Nowadays, temporary organisations as projects, programmes and various participatory organisational forms are found in diverse economic industries, private and public sectors.

By definition, the temporary organisation is "a set of organisational actors working together on a complex task over a limited period of time" (Grabher 2002; Jones 1996; Meyerson et al. 1996, cited in Bakker 2010: 468).

Temporary forms of organising differ from permanent structures by their temporariness, uniqueness, heterogeneity and fixed time orientation (Pauget, Wald 2013). To Powell (1990), temporary and network based organisational forms represent viable economic entities based on structural role systems. Task based roles are considered as basic units of socialisation within the project environment (Bechky 2006). They are deemed as central components of the continuity of network-based organisations. Temporary organisations are governed through intra- and inter-organisational relationships. Managing these multilayer relationships as complex networking systems requires well established holistic strategic management approach and efficient reciprocal communication to enable effective interaction, knowledge and information exchange experience.

From purely theoretical standpoint, the framework of a temporary organisation is defined by several crucial components, namely, time, task, team and transition. These components are characteristics for setting the boundaries between the temporary organisation and various other types of organisational forms and their environment (Lundin, Söderholm 1995). To Gemünden (2013: 2) "projects are temporary organisations, 
strongly focused on a defined task, and therefore very agile. Projects, however, are also very fragile, with regard to the knowledge gained through a project, which quickly evaporates after disbanding the project team. Project management offices are seen as a means to overcome this problem by actively sharing and storing know-who, know-what, and know-how".

In order to successfully manage temporary organisations, there is a need of "social mechanisms such as reciprocity, socialization, reputation" (Jones et al. 1990, cited in Bechky 2006: 3). Therefore, communication and its quality start playing a strategic role in order to ensure the accomplishment of project goals and business needs, and meet the expectations of stakeholder groups through needs-based and task-oriented collaboration, knowledge sharing and meaningful professional socialization.

In project management literature, the responsibility for project success or failure often is attributed to communication structures and practices (M. B. Pinto, J. K. Pinto, 1990; Kliem 2008; Bond-Barnard et al. 2013). Although communication is deemed as an indivisible part of project management, there is still a limited number of articles discussing communication as a strategic management pattern that enables to connect, inform and engage people in activities of projects and their environment (Johannessen, Olsen 2011; Lehman 2009; Dainty et al. 2006, cited in Bond-Barnard et al. 2013).

By definition, the main purpose of communication is "the transfer of information, involving a person or entity sending out a message and another receiving and a successful understanding of the message in response" (Torrington, Hall 1998, cited in Bond-Barnard et al. 2013: 3). It plays an important mediating role and is an essential foundation for successful human interaction (Marques 2010) that leads to relationship quality. Communication shapes such characteristics as interpersonal trust, commitment, coordination and collaboration (Sheng et al. 2005).

Authors who specialise in "project communication" underline that often attention is given to the question of "why" communication is important in project management rather than expanding knowledge regarding "how" to communicate effectively (Ramsing 2009; Johannessen, Olsen 2011; Bond-Barnard et al. 2013).

The term "project communication" is deemed as an ongoing process embracing all aspects of communication in projects whether they occur in relation to project tasks or people, internally and externally (Ramsing 2009). Communication in projects is deemed as the strategic link that helps building a bridge between an organisation and individuals temporarily involved in project work to achieve business goals. According to Kliem (2008), communication in project management is guided by five basic principles as 1) people not media play a far more important role in communication process; 2) communication is an ongoing process throughout all stages of the project life-cycle; 3 ) it is contextual and can be affected by factors from the external environment 4) communication can take various forms and occurs at different levels; and 5) communication is about information rather than data (Kliem 2008).

Communication plays a strategic role as it is a powerful coordinating social mechanism that enables collaborative relations and networking at different levels of the organisa- 
tional arena and ultimately serve a variety of business needs. Communication is responsible for coping with systemic dependence and tensions of elements found in projects as temporary social systems emerging from the existing permanent organisations (Johannessen, Olsen 2011). Communication effectiveness can be affected by the increased rate of complexity of projects, globalization of projects, expansion of innovation-driven horizontal networks participating in project work (Flyvberg 2007, cited in Johannessen, Olsen 2011; Morris, Pinto 2004; Oke, Idiagbon Oke 2010).

In the environment of temporary organisations, communication is taken for granted to serve project related needs that often are shaped by various obligations and intents specific for temporary organisations to ensure distribution and exchange of information, coordinating of task-oriented activities. From the strategic management point of view, the communication within the environment of temporary organisations often crosses the boundaries of project related needs and is an instrument to create mutual understanding, building collaborative relations, influencing and socializing (Poole 2005, cited in Johannessen, Olsen 2011). This way, communication in temporary organisations is the enabler of various social capital gains for the parent organisation through implemented projects. Therefore, collaborative communication in temporary organisations could be viewed from the perspective of three different levels as 1) within projects; 2) between projects; 3) across company or industry information exchange. In addition, it is suggested to differentiate communication modes with respect to specific categories of needs, as 1) communication which is driven by the project participant's operational needs to collaborate; 2) with intention to share accumulated knowledge; 3) to ensure common understanding in regard of the project scope (Senescu et al. 2011).

The general definition of effective communication is founded on the idea of shared understanding about information aiming to minimise misunderstanding, conflicts, and errors between people or groups of people interacting, working towards a common objective (Dennis et al. 2008). According to Macaulay (1997), cited in Coughlan, Macredie (2002), the main causes that lead to failure to communicate effectively should be associated with such three categories as process, interaction and expectations. To build effective communication in the business environment requires identification of the clear purpose of communication. The contextual business needs are considered as an appealing component and an important driving force for effective communication (Pavia et al. 2011). Improvements in the effectiveness of communication within environment of projects usually tend to expand existing boundaries and lead to: 1) increased performance of projects and organisations; 2) empowered responsibilities and ownership of tasks; 3 ) promoting open exchange of information breaking down professional, organisational and cultural boundaries; 4) costs and time savings (Emmitt, Gorse 2007). Building of effective communication requires consideration and evaluation of a set of components and their interactions in order to close communication gaps.

Business related needs are a foundation required for functioning of any organisational setting. The task of effective communication is to satisfy business needs and expectations. In the environment of temporary organisations, the open systems needs are based on project goals. In this relation, Johannessen and Olsen (2011) emphasise that each 


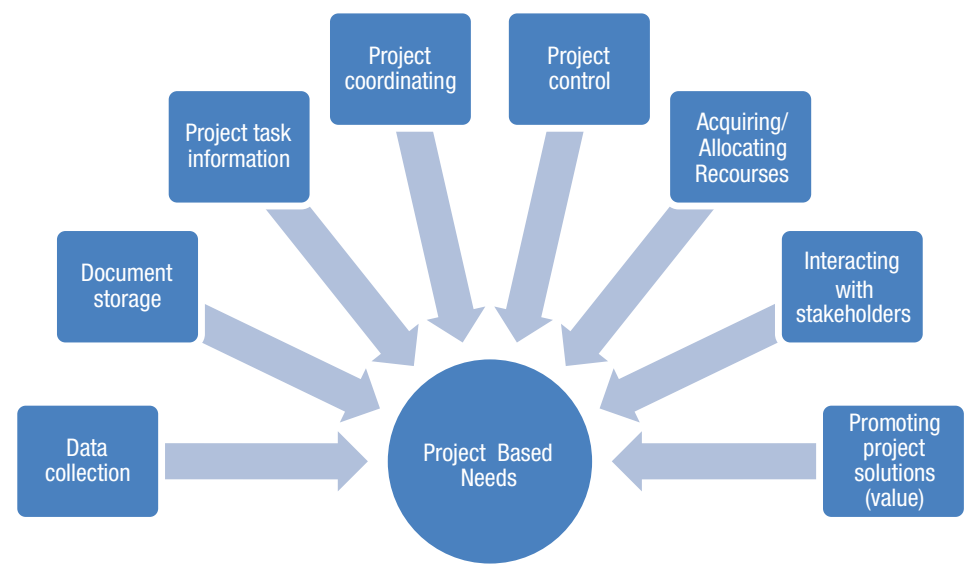

Fig. 1. Typology of project-based needs (adapted by authors from Johannessen, Olsen 2011)

different segment of the project at a different project lifecycle stage and level requires information of different value to address the specific operational and strategic needs of the temporary organisation as a whole. A range of functional project needs were distinguished which are presented in Figure 1.

\subsection{Social media in communication of temporary organisations: theory and practice}

The outbreak of social media in recent years is transforming not only private, but also business communication patterns. Although social media are not considered as a revolutionary instrument today, they still have relatively narrow application in the project business world (Walker 2013).

As new age communication tools, social media are on fast rise. Statistics report the growing numbers of users of social media tools every year. For example, it is said that in 2013, the number of Facebook users increased up to 1.2 billion, Twitter shows an impressive growth by $44 \%$ just in one year and has around 500 million users, Google+ base grew by $33 \%$ and is a host platform for 359 million accounts (Susskind 2013; Socialbakers 2013). The current market situation and use of diverse social media platforms in 2013 is presented in Figure 2. Social media is regarded as a set of tools that enable sharing of user-generated material and establishing relationships online (Fischer, Reuber 2011: 2).

Social media form a new world that does not recognise limits in distance, sound spreads at the speed of light and all experiences are in real-time. Social media channels are userfriendly, inexpensive, scalable internet- and mobile-based technologies, also described as "content oriented and participative type facilitators for collaborative conversations on large scale" (Fischer, Reuber 2011).

Although there is no unanimously recognized social media typology, it is acknowledged that social media tools vary greatly in terms of their functional design and size. It is 
common to differentiate them between social networking (e.g. Facebook), social tagging (bookmarking), video-sharing (e.g. YouTube/Vimeo), picture-sharing (e.g. Flickr), professional networking (e.g. LinkedIn), user forums, blogs and microblogging (e.g. Twitter), feeds, crowd-sourcing (Fischer, Reauber 2011).

According to Trainor (2012), emergence of social media technologies have enabled new communication capabilities in various aspects, which are presented in Figure 3.

By combining different elements and their functional features, social media are recognized as very powerful means that embrace the 5C's comprising such principle elements and characteristics as community, conversation, contribution, collaboration, connection that organise the logical framework of social media.

Project management and social media share similar concepts in terms that they both are strongly focused on "communication" and "engagement" (Stronach 2012). Specifics of projects greatly require mechanisms that would help inspire participants to communicate

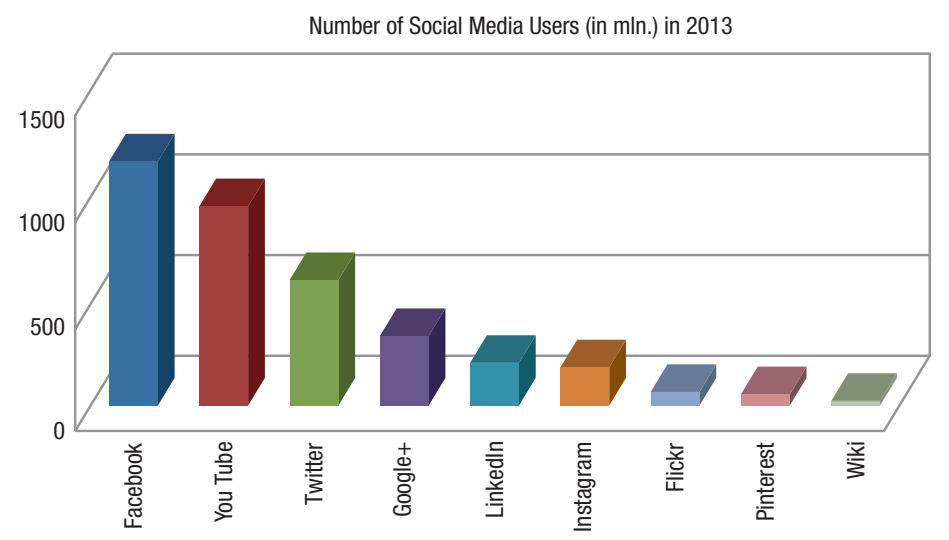

Fig. 2. Usage of social media in 2013

Data source: Suskind (2013); Socialbakers (2013).
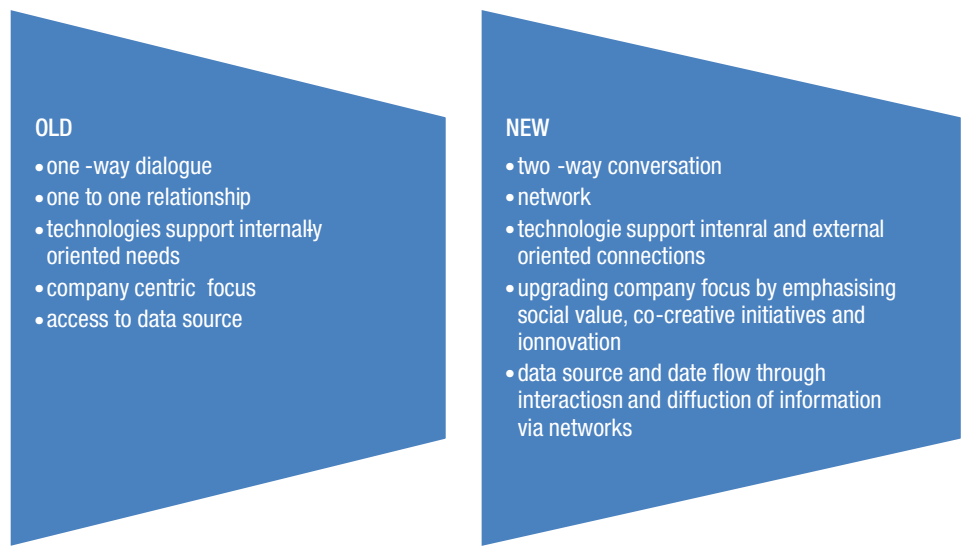

Fig. 3. Changes in communication capabilities due to social media technologies 
actively. Taking into account an increasing number of virtual project teams worldwide, quick, cheap and efficient channels are particularly important nowadays. Social media can be useful for building the identity of the team involved in collaborative relationships; can be effective instruments for stakeholder management. Besides, social media can largely contribute to increase in project influence and visibility internally and externally.

On the contrary, the skeptics often point to the potential risks and challengesassociated with social media. To Mullaly (2012: 1), "ubiquity of the internet, the anonymity of the internet and what can be best referred to as the lack-of-politeness of the internet" is the main reason why organisations are reserved regarding social media. The other reason is the lack of experience and confidence in professional and proper use of open channels, which often keeps temporary organisations away from employing social media as supplemental tools for communication.

\section{Research on use of social media for communication in a temporary organisation}

The research study is built on the following mixed research path. Selection of mixed research methods as a methodology was significantly influenced by the unique and complex context and the practical nature of the research questions.

The research is based on opinions of experts and professionals. The target audience consisted of professionals who met the following criteria: 1) the professional experience in project work (no less than 5 years); 2) project complexity in terms of project funding source and size of a team; 3 ) the role undertaken in projects from 11 different countries. They were interviewed or participated in a web-based survey. The Majority of participants and respondents belong to the European Union countries $(80.70 \%)$ and obviously lower proportion of representatives (19.30\%) from non-EU countries, including Australia, Thailand, Kazakhstan and others (Fig. 4).

In terms of gender, females constituted $59.7 \%$ against $40.3 \%$ of males. Regarding the age of respondents, the bulk of the sample (48.3\%) belonged to the age group of up to 34 years of age, while (12.9\%) were in the age group of 35-45, and (38.8\%) were representatives over 45 years with a combined proportion being 55 years and above. In terms of distribution by economic sector, respondents represented a mix of business sectors. The largest portion of respondents accounting for $37.1 \%$ was involved in social, health, education and culture sectors. It is followed by the second largest group of respondents $(17.7 \%)$ who were involved in business/financial sector and, finally, the third group of participants $(45.2 \%)$ composed of those involved in a mix of economic sectors.

In terms of research design, the sequential exploratory research design model was applied aiming to achieve two goals. Firstly, to collect experience in order to acquire a better understanding of the situation which is relatively new in project environments. Secondly, to develop a web-based survey on the foundation of collected results and insights during the first stage in order to reach a larger population of professionals and with the intention to ultimately generalize findings to provide recommendations. 
The research related data was collected by organising semi-structured interviews and the web-based survey. A set of variables involved in the research were applied to cover the identified project-based communication needs and relevant factors meaningful and important to the research context.

The source of the secondary type data included diverse academic articles, professional magazines and other literature, as well as online forums and discussion boards, webinars.

The quantitative stage of data collection started as soon as the first stage was completed as presented in Figure 5.

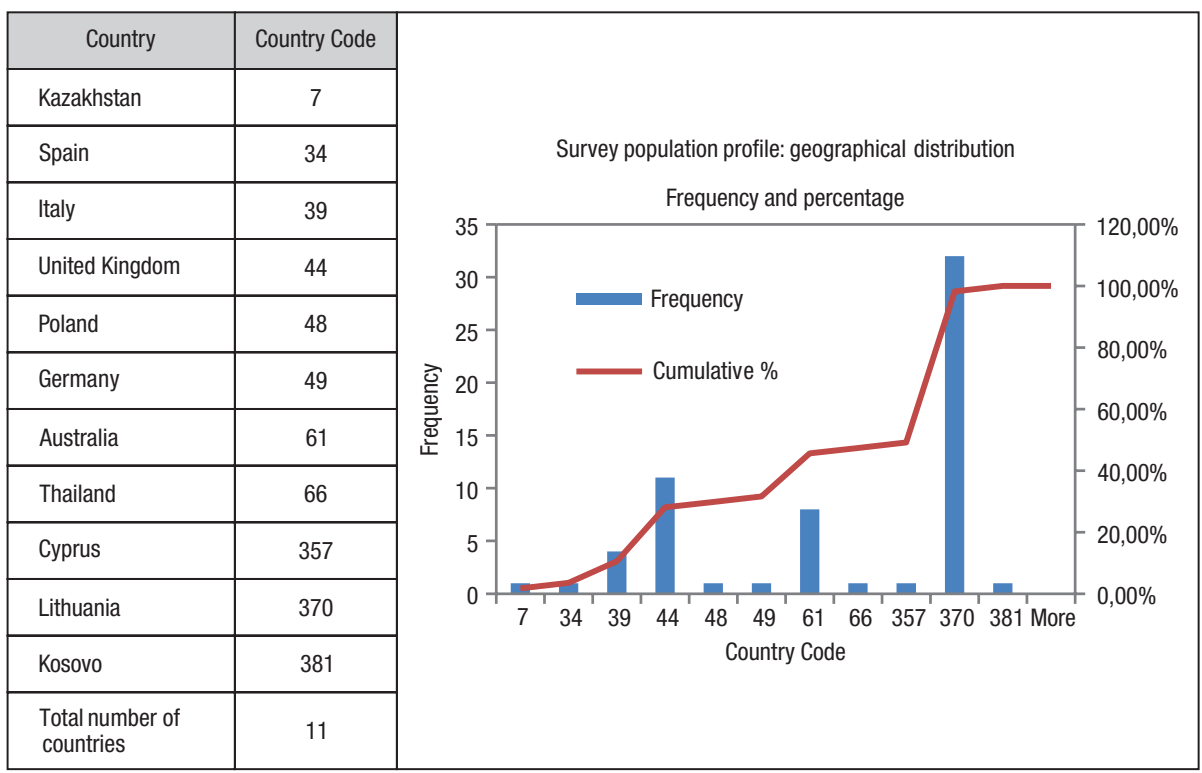

Fig. 4. Profile of the sample population: distribution by countries

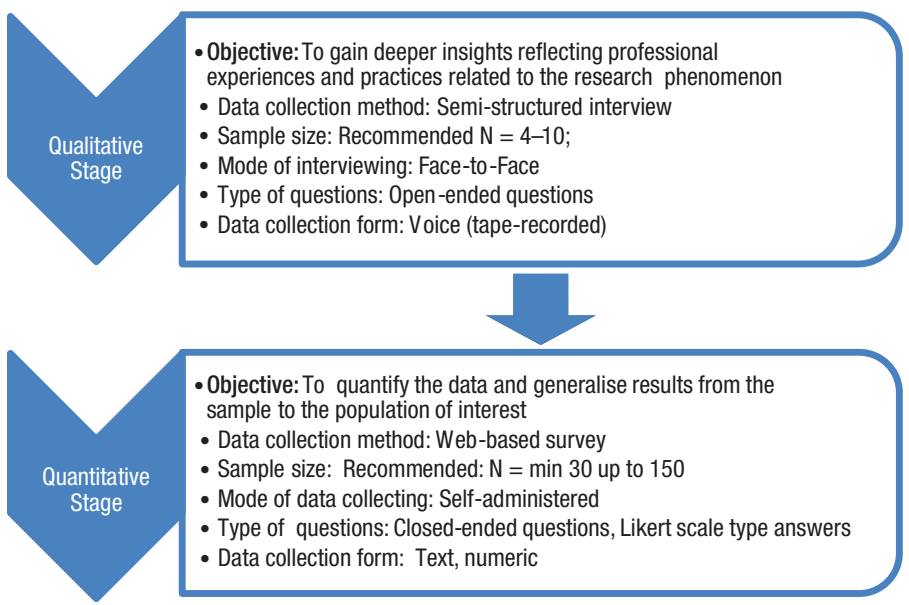

Fig. 5. Research data collection phases 


\section{Findings and results of research investigating need-oriented communication in temporary organisations}

The collected evidence supported efforts in finding answers for the distinguished research objectives.

Objective 1. The first objective was to establish communication modes common in the environment of temporary organisations.

Use of traditional communication modes as the direct communication $(71.0 \%)$ and emails $(83.9 \%)$ as well as telephone-based communication $(80 \%)$ are still preferred communication means in the environment of temporary organisations. One third (32.3\%) of respondents use Intranet. The research points to a low use of social networking platforms that are used often or sometimes by only $11.3 \%$ and $22.6 \%$ respondents, respectively.

The established low rate of use of social media tools in temporary organisations is a likely signal about potential constraints that keep temporary organisations off using social media tools at a larger scale.

Objective 2. The second objective of the research was to identify the means of social media participating in communication of temporary organisations.

The social media world today has many applications to offer (Fig. 7). Identified gaps related to the use of various social media platforms for business and personal needs (Fig. 8) clearly indicate to many social media tools being used for personal purposes but still remaining under-employed in terms of project related business needs.

Research findings show that Facebook, Google + and LinkedIn are the most employed networking tools in temporary organisations. Twitter (4.8\%), which is praised for its specific functional features and is recommended as a good monitoring application, is

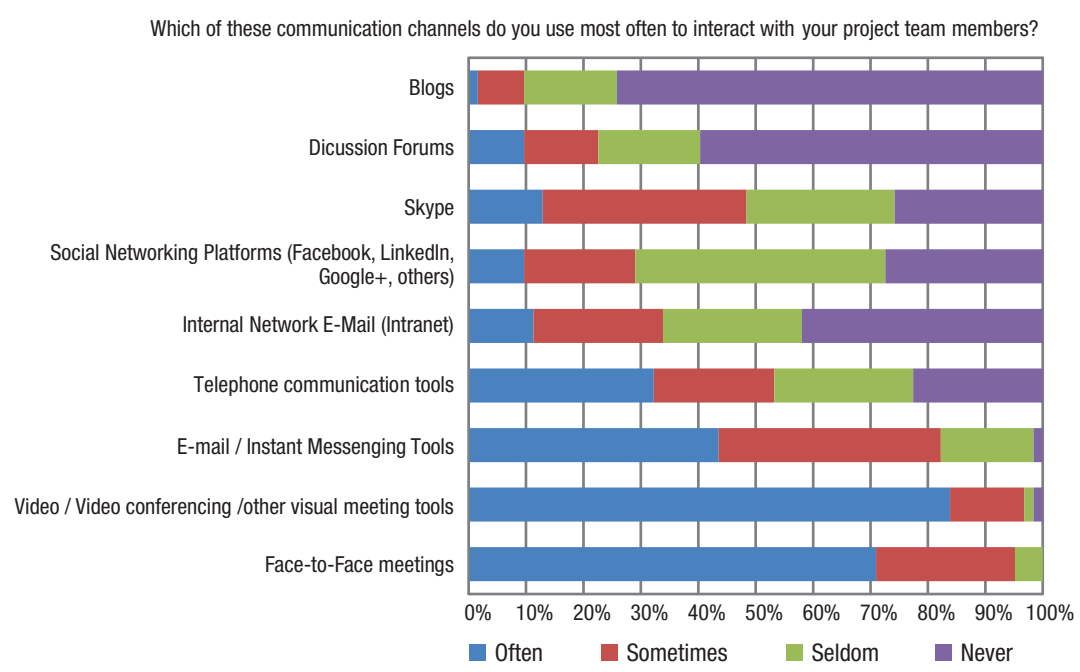

Fig. 6. Communication modes in project communication 


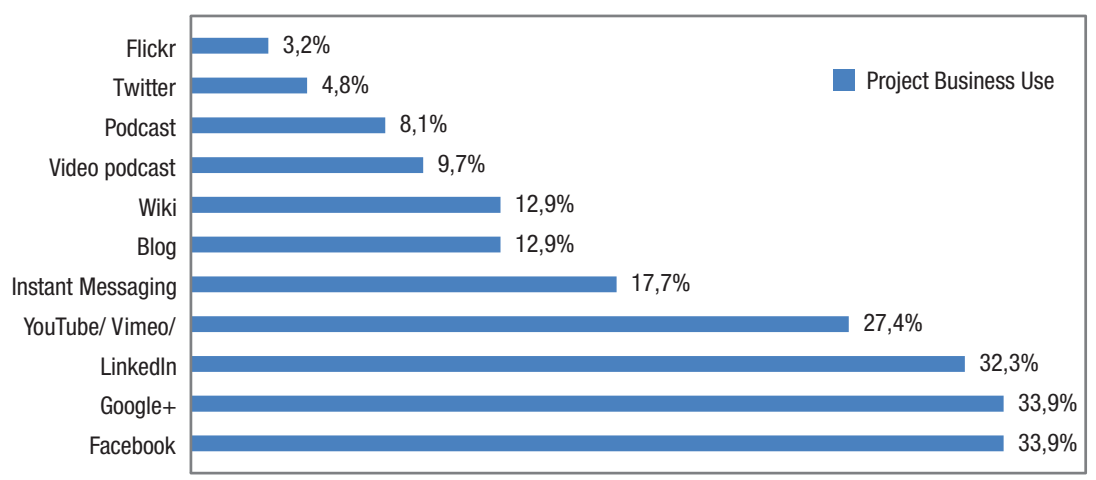

Fig. 7. Usage of social media channels

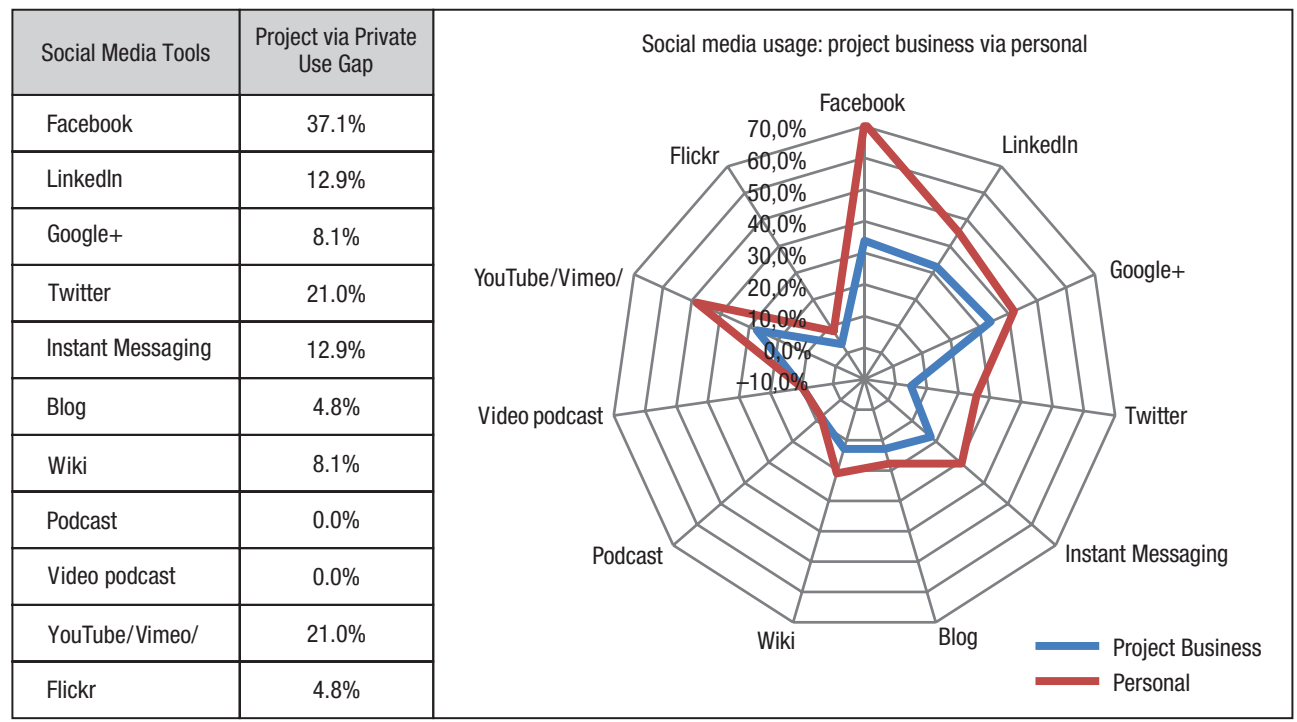

Fig. 8. Social media usage with purpose of project business needs

still remains under-used for project communiciation. The blog, as an instrument of special collaborative and knowledge sharing type, is also likely to be valued at a low rate. It is likely, that the use of social media highly depends on the extent of realised tangible benefits deriving from "social dialogue" at business or personal levels.

Objective 3. The third objective was to examine the perceptions in regards to social media use to improve the effectiveness of communication in temporary organisations.

Perceptions, expectations are important for identification of opportunities to improve communication by using social media with respect to project-based needs.

As findings (Table1) show, social media have a great potential to be applied and improve the effectiveness of communication in all major project work related areas. The 
Table 1. Actual and perceived application of social media tools in project communication

\begin{tabular}{lccc}
\hline \multicolumn{1}{c}{ Application area and purpose } & $\begin{array}{c}\text { Current } \\
\text { application }\end{array}$ & $\begin{array}{c}\text { Perceived } \\
\text { application }\end{array}$ & Potential \\
\hline Data collection & $48.3 \%$ & $92.98 \%$ & $-44.68 \%$ \\
\hline Document storage & $13.8 \%$ & $52.73 \%$ & $-38.93 \%$ \\
\hline Exchanging task-related information & $34.5 \%$ & $89.09 \%$ & $-54.59 \%$ \\
\hline Project coordinating & $24.1 \%$ & $89.29 \%$ & $-65.19 \%$ \\
\hline Project control & $12.1 \%$ & $76.92 \%$ & $-64.82 \%$ \\
\hline Acquiring/allocating recourses & $12.1 \%$ & $83.33 \%$ & $-71.23 \%$ \\
\hline Sharing knowledge with the team members & $44.8 \%$ & $90.91 \%$ & $-46.11 \%$ \\
\hline Interacting with stakeholders, end-users & $41.4 \%$ & $87.27 \%$ & $-45.87 \%$ \\
\hline Enhancing professional competence & $15.5 \%$ & $87.27 \%$ & $-71.77 \%$ \\
\hline Promoting innovation/ project value & $29.3 \%$ & $91.23 \%$ & $-61.93 \%$ \\
\hline
\end{tabular}

greatest benefits of using social media are found is the following areas and with purpose of: project coordination $(65.9 \%)$ and project control $(64.82 \%)$, acquiring recourses (71.23\%), enhancing professional competence $(71.77 \%)$, as well as promoting innovation as project based solutions (61.93\%).

At present, social media are utilized mostly with the purpose to collect data $(48.3 \%)$, to share knowledge with team members $(44.8 \%)$, interact with stakeholders or end-users (41.4\%), exchanging task-related information (34.5\%) as it is indicated in Figure 9.

The research revealed a range of opinions and approaches in regard to perceived benefits of social media use for project communication. However, summarised results indicate that, undoubtedly, project practitioners demonstrate an increasing interest in a wider

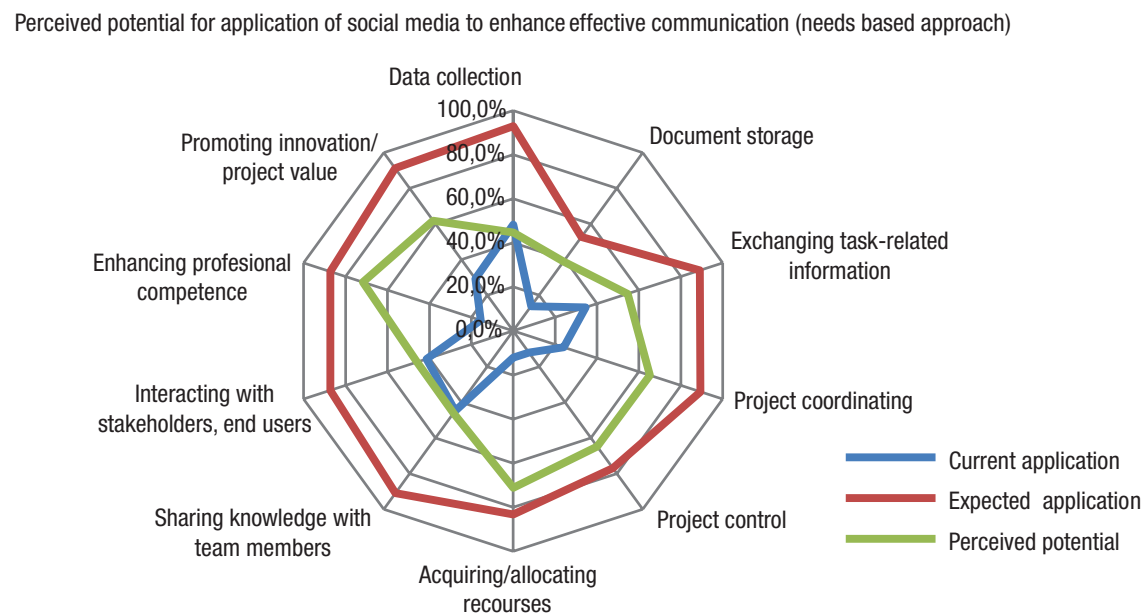

Fig. 9. Potential application of social media in temporary organisations 
application of social media tools in various areas of their work. According to their opinion, social media will be on the rise in 2-3 years in project environment and they will contribute to the effectiveness of communication in temporary organisations at least in terms of time and costs.

Objective 4. The fourth objective was to identify the barriers/reservations to use social media in communication in temporary organisations.

The explosion of social media in various businesses in recent years on one hand, and on the opposite, their moderate application in communication of temporary organisations point to existence of possible constraints. The majority of respondents $(84.5 \%)$ indicated that using social media tools in professional manner and for professional purpose requires supplemental users skills.

To use social media confidently, a supplemental training is needed. Training would support efforts aimed at building a shared understanding in regards to social media, their appropriate use in the alignment to overall goals of temporary organisations.

In summary, approaching this research from less theoretical but moremanagerial position, we conclude that overall survey results indicate that social media use can enhance effectiveness of communication in temporary organisations. Temporary organisations still embrace a low range of social media tools in their work related practices. Underexploited social media channels in project communication may bring substantial value in various project related areas by meeting a set of project-based needs that require reciprocity, real-time coordination and control, flexibility acquiring recourses and creative ways of project value promotion. By using social media, temporary organisations can capitalise on time and cost saving opportunities organising and managing their communication in more effective way. However, effectiveness of communication based on social media interactions in temporary organisations should be founded on professional norms and skills to be acquired through supplemental training.

Taken as a whole, the authours admit that having studied general trends of social media use in communication of temporary organisations, they were unable to cover a wider scope and embrace a large cross-cultural context, which requires regular investigation. A more complimentary research would require significantly greater amout of time and recourses. Limitations revealed in this paper can be regarded as motivation for further research in this area.

\section{Conclusions}

1. Social media use in communication of temporary organisations requires a holistic approach viewing it either from the practical or theoretical perspective. In practical terms, the growing interest in social media among project professionals calls to rethink communication management strategy in contribution to building collaborative relationships within project teams and stakeholder management.

2. From the perspective of project practitioners, social media, as a new mode of communication, should be approached with the question: How can they aid us? Project managers should investigate perceptions of their employees in regards to the quality 
of information exchange and their communication needs. In this light, it is management's responsibility to worry about an effective mapping of project-related needs matching the specific social media tools. Relevant selection of social media channels would lead to well planned, effective communication with the purpose to meet project goals to the best.

3. The moderate social media application in communication of temporary organisations leads to the idea about possible constraints. Through the combined findings of this research, it was established that there is a realised need to increase professional confidence by gaining supplemental skills to use social media effectively. In reality, this means that social media application has a great potential of development within the environment of temporary organisations.

4. From a theoretical standpoint, this research study is deemed as a meaningful initiative to address an up-to-date topic for business. It is likely that due to the complexity of two overlapping phenonomena - social media and the temporary organisation - the topic can offer many interesting insights that would lead to building a solid theoretical model in the future.

\section{References}

Bakker, B. 2010. Taking stock of temporary organisational forms: a systematic review and research agenda, International Journal of Management Reviews 12: 466-486.

http://dx.doi.org/10.1111/j.1468-2370.2010.00281.x

Bechky, B. 2006. Gaffers, gofers, and grips: role-based coordination in temporary organisations, Organisation Science 17(1): 3-21. http://dx.doi.org/10.1287/orsc.1050.0149

Bond-Barnard, T. J.; Steyn, H.; Fabris-Rotelli, I. 2013. The impact of a call centre on communication in a programme and its projects e impact of a call centre on communication in a programme and its projects, International Journal of Project Management 31(7): 1006-1016.

http://dx.doi.org/10.1016/j.ijproman.2012.12.012

Coughlan, J.; Macredie, R. 2002. Effective communication in requirements elicitation: a comparison of methodologies, Requirements Engineering 7(2): 47-60.

http://dx.doi.org/10.1007/s007660200004

Dennis, A.; Fuller, R.; Valacich, J. 2008. Media, tasks, and communication processes: a theory of media synchronicity, MIS Quarterly 32(3): 575-600.

Gemünden, H. G. 2013. From the editor, Project Management Journal 44(2): 2-3.

Emmitt, S.; Gorse, C. 2007. Communication in construction teams. $1^{\text {st }}$ ed. New York: Taylor \& Francis. http://dx.doi.org/10.1002/pmj.21335

Fischer, E.; Reuber, A. 2011. Social interaction via new social media: (how) can interactions on Twitter affect effectual thinking and behavior?, Journal of Business Venturing 26: 1-18. http://dx.doi.org/10.1016/j.jbusvent.2010.09.002

Johannessen, J.; Olsen, B. 2011. Projects as communicating systems: creating a culture of innovation and performance, International Journal of Information Management 31: 30-37.

http://dx.doi.org/10.1016/j.ijinfomgt.2010.04.006

Kliem, L. R. 2008. Effective communications for project management. Boca Raton: Taylor \& Francis Group.

Lundin, R.; Söderholm, A. 1995. A theory of the temporary organisation, Scandinavian Journal of Management 1(4): 437-455. http://dx.doi.org/10.1016/0956-5221(95)00036-U 
Marchi, S.; Sarcina, R. 2011. Temporariness in appreciative reflection: managing participatory and appreciative, action and reflection projects through temporary organisations, Reflective Practice 12(2): 159-177. http://dx.doi.org/10.1080/14623943.2011.561529

Marques, J. 2010. Enhancing the quality of organisational communication: a presentation of reflection-based criteria, Journal of Communication Management 14(1): 47-58.

http://dx.doi.org/10.1108/13632541011017807

Mckinsey.com. 2014. Organizing for Change Through Social Technologies: McKinsey Global Survey results [online], [cited 14 January 2014]. Available from Internet: http://www.mckinsey. com/insights/high_tech_telecoms_internet/organizing_for_change_through_social_technologies_ mckinsey_global_survey_results

Morris, P.; Pinto, J. 2004. The willey guide to managing projects. New Jersey: John Willey \& Sons, Inc. http://dx.doi.org/10.1002/9780470172391

Mullaly, M. 2012. The Social Storm [online], [cited 14 January 2014]. Available from Internet: http://www.projectmanagement.com/articles/271280/The-Social-Storm

Oke, A.; Idiagbon-Oke, M. 2010. Communication channels, innovation tasks and NPD project outcomes in innovation-driven horizontal networks, Journal of Operations Management 28: 442-453. http://dx.doi.org/10.1016/j.jom.2010.01.004

Pavia, P.; Pinjani, P.; Cannoy, S.; Jacks, T. 2011. Contextual constraints in media choice: beyond information richness, Decision Support Systems 51: 657-670.

http://dx.doi.org/10.1016/j.dss.2011.03.006

Pauget, P.; Wald, A. 2013. Relational competence in complex temporary organisations: the case of a French hospital construction project network, International Journal of Project Management 31: 200-211. http://dx.doi.org/10.1016/j.ijproman.2012.07.001

Pinto, M. B.; Pinto, J. K. 1990. Project team communication and cross-functional cooperation in new program development, Journal of Product Innovation Management 7(3): 200-212.

http://dx.doi.org/10.1016/0737-6782(90)90004-X

Powell, W. 1990. Neither market nor hierarchy: network forms of organisation, Research in Organisational Behavior 12: 295-336.

Ramsing, L. 2009. Project communication in a strategic internal perspective, Corporate Communications: an International Journal 14(3): 345-357. http://dx.doi.org/10.1108/13563280910980113

Senescu, R.; Aranda-Mena, G.; Haymaker, J. 2011. Relationhip between project complexity and communication. Complexity and communication. CIFE Technical Report \#TR196. Stanford, Stanford University.

Sheng, S.; Brown, J. R.; Nicholson, C. Y. 2005. The mediating role of communication in interorganisationl channels, Journal of Marketing Channels 13(1): 51-80.

Socialbakers, N. D. 2013. Twitter Statistics \& Current Number of Followers \& Following [online], [cited 14 January 2014]. Available from Internet: http:/www.socialbakers.com/twitter/

Stronach, M. 2012. Socially Acceptable Project Management [online], [cited 14 January 2014]. Available from Internet: http://www.projectmanagement.com/articles/272364/Socially-Acceptable-Project-Management

Susskind, J. 2013. 12 Social Media Stats of 2013 You Didn't Know - the Social Ballot [online], [cited 14 January 2014]. Available from Internet: http://ivn.us/social-ballot/2013/07/24/12-socialmedia-stats-of-2013-you-didnt-know/

Trainor, K. 2012. Relating social media technologies to performance: a capabilities-based perspective, Journal of Personal Selling \& Sales Management 32(3): 317-331.

http://dx.doi.org/10.2753/PSS0885-3134320303

Walker, N. 2013. Can Social Media Help to Deliver Projects in 2013 [online], [cited 14 January 2014]. Available from Internet: http://ppmpractitioner.wordpress.com/2013/06/14/social-media/ 
Dalia RIMKUNIENE. MSc Strategic Project Management, Heriot-Watt University, Edinburgh, International Master Studies In Economics of Culture, Tor-Vergata University (CEIS), Rome, independent researcher with a proven track record of success spanning project co-ordination and management roles in the corporate, tourism, international cultural and business events sectors. At present engaged as a project consultant and researcher of international project I D E A T E HighTechInterdisciplinary Entrepreneurial Application for Transforming Education in High Technologies. Science interest in strategic management, project management and social media.

Virgilija ZINKEVICIUTE. Doctor of Social Science, Associated Professor of Logistics and Transport Management Department; Business Technology Department of Vilnius Gediminas Technical University, science interest in strategic and quality management, an active participant and researcher in international and national projects; an initiator and developer of students entrepreneurial skills. She is a Visiting Professor at various universities in Finland, Holland, Belgium, Turkey and Portugal. 